\title{
The Effect of Treatment of Clinical Endometritis on Reproductive Performance in Dairy Cows
}

\author{
S. J. LeBlanc, ${ }^{*}$ T. F. Duffield, ${ }^{\star}$ K. E. Leslie, ${ }^{\star}$ \\ K. G. Bateman, ${ }^{\star}$ G. P. Keefe, $\dagger$ \\ J. S. Walton, $\ddagger$ and W. H. Johnson* \\ *Department of Population Medicine and $\ddagger$ Department of Animal and Poultry Science \\ University of Guelph, Ontario, Canada N1G 2W1 \\ †Department of Health Management, University of Prince Edward Island, Charlottetown, Canada C1A 4P3
}

\begin{abstract}
The objective of this field trial was to compare the effect of intrauterine (i.u.) antibiotic or intramuscular (i.m.) prostaglandin $\mathrm{F}_{2 \alpha}\left(\mathrm{PGF}_{2 \alpha}\right)$ on time to pregnancy in dairy cows diagnosed with clinical endometritis between 20 and 33 days in milk (DIM). The case definition of endometritis was the presence of purulent uterine discharge or cervical diameter $>7.5 \mathrm{~cm}$, or the presence of muco-purulent discharge after 26 DIM. There were 316 cows with endometritis from 27 farms assigned randomly within herd to receive $500 \mathrm{mg}$ of cephapirin benzathine intrauterine (i.u.), $500 \mu \mathrm{g}$ of cloprostenol i.m., or no treatment. The rate of resolution of clinical signs $14 \mathrm{~d}$ after treatment was $77 \%$ and was not affected by treatment. Reproductive performance was monitored for a minimum of $7 \mathrm{mo}$ after treatment. Survival analysis (multivariable proportional hazards regression) was used to measure the effect of treatment on time to pregnancy. There was no benefit of treatment of endometritis before $4 \mathrm{wk}$ postpartum. Administration of $\mathrm{PGF}_{2 \alpha}$ between 20 and 26 DIM to cows with endometritis that did not have a palpable corpus luteum was associated with a significant reduction in pregnancy rate. Between 27 and 33 DIM, cows with endometritis treated with cephapirin i.u. had a significantly shorter time to pregnancy than untreated cows (hazard ratio $=1.63$ ). In this time period, there was no difference in pregnancy rate between $\mathrm{PGF}_{2 \alpha}$ and untreated cows, but the difference in pregnancy rate between cows treated with cephapirin i.u. and with $\mathrm{PGF}_{2 \alpha}$ was not statistically significant. Treatment of postpartum endometritis should be reserved for cases diagnosed after 26 DIM, based on criteria that are associated with subsequent pregnancy rate.
\end{abstract}

Received November 23, 2001.

Accepted February 3, 2002.

Corresponding author: S. J. LeBlanc; e-mail: sleblanc@ovc. uoguelph.ca.
(Key words: endometritis, reproductive performance, intrauterine antibiotic, prostaglandin $\mathrm{F}_{2 \alpha}$ )

Abbreviation key: $\mathbf{C L}=$ corpus luteum, $\mathbf{H R}=$ hazard ratio, i.u. $=$ intrauterine.

\section{INTRODUCTION}

Reproductive performance is one key component of dairy production management. Diagnosis and treatment of postpartum uterine disease, and its putative impact on reproductive performance, have traditionally attracted considerable attention from veterinarians and producers. Endometritis is a localized inflammation of the uterine lining, associated with chronic postpartum infection of the uterus with pathogenic bacteria, primarily Arcanobacterium pyogenes (Bondurant, 1999). Diagnostic criteria to identify cows that have impaired reproductive performance associated with clinical endometritis have been examined (LeBlanc et al., 2002). Treatment of endometritis is the subject of considerable controversy among veterinary practitioners, particularly with respect to which therapy to use, and to a lesser extent, which cows to treat, or whether to treat at all (Gilbert, 1992). The general principle of therapy of endometritis is to halt and reverse inflammatory changes that impair fertility. Practically, treatments aim to reduce the load of pathogenic bacteria and enhance the processes of uterine defense and repair.

A wide variety of therapies for endometritis have been reported, including systemic or local antibiotics, as well as systemic prostaglandin $\mathrm{F}_{2 \alpha}\left(\mathrm{PGF}_{2 \alpha}\right)$ or estradiol. Treatment of postpartum endometritis has been reviewed (Gustafsson, 1984; Bretzlaff, 1987; Gilbert and Schwark, 1992; Olson, 1996). Well-designed, large-scale clinical trials with objective case definitions and economically meaningful outcomes are lacking. Many therapeutic trials suffer from a lack of negative controls, small numbers of animals resulting in little statistical power, or both. Most investigations have used diagnostic criteria for endometritis that 
were not validated as to their effect on reproductive performance, making it difficult or impossible to discern a true treatment effect. Some studies have used clinical or bacteriologic cure as the endpoint (Callahan and Horstman, 1993; Dohmen et al., 1995; Brooks, 2000 ), rather than economically relevant measures of reproductive performance: the probability and timing of pregnancy. Moreover, many studies have reported measures of reproductive performance that were biased or incorrectly analyzed statistically. There is little evidence for a benefit of any intrauterine (i.u.) antimicrobial on reproductive performance in cows with endometritis (Steffan et al., 1984; Thurmond et al., 1993), but some evidence that routine postpartum use of $\mathrm{PGF}_{2 \alpha}$ reduces time to pregnancy (Etherington et al., 1988; Risco et al., 1994). Most comparative clinical trials (Steffan et al., 1984; Sheldon and Noakes, 1998) and reviews (Gilbert and Schwark, 1992; Olson, 1996) have concluded that $\mathrm{PGF}_{2 \alpha}$ is at least as effective as or is preferable to i.u. infusion of antimicrobials for treatment of endometritis. However, there remains a lack of compelling results on this question, and i.u. administration of antibiotics to dairy cows remains common.

Recent approval of an i.u. antibiotic labeled for treatment of endometritis with zero milk withdrawal afforded the opportunity to carry out a large-scale field comparison of i.u. antibiotic to $\mathrm{PGF}_{2 \alpha}$ injection for treatment of endometritis in commercial dairy herds. The goal of this study was to compare approaches to treatment of clinical endometritis that are commonly used in veterinary practice, including a negative control. The specific objective was to evaluate the effect on reproductive performance of a single administration of i.u. antibiotic (cephapirin benzathine) or i.m. $\mathrm{PGF}_{2 \alpha}$ (cloprostenol) in the postpartum period as therapy for endometritis in dairy cows.

\section{MATERIALS AND METHODS}

The full details of the study population and examination protocol have been reported previously (LeBlanc et al., 2002). Briefly, all Holstein cows in 27 herds were routinely examined once between 20 and 33 DIM, inclusive. History of veterinary- assisted parturition, twin birth, retained placenta for $>24 \mathrm{~h}$, or metritis (systemic illness referable to uterine infection) in the current lactation were recorded. Examination included inspection of the vulva, tail, and perineum; vaginoscopy; and trans-rectal palpation of the cervix, uterus, and ovaries. Uterine discharge was classified as clear mucus, mucus with flecks of pus, muco-purulent, or purulent. The case definition for endometritis was the presence of purulent uterine discharge or cer- vical diameter $>7.5 \mathrm{~cm}$ throughout the enrollment period, or muco-purulent discharge after 26 DIM. These diagnostic criteria were shown (LeBlanc et al., 2002) to identify cows with significantly decreased pregnancy rates. There were 316 cows with endometritis from a total of 1865 cows examined (16.9\%). Upon diagnosis, those animals were randomly assigned to immediately receive either $500 \mathrm{mg}$ of cephapirin benzathine in 19.6$\mathrm{g}$ ointment base (Metricure, Intervet, Boxmeer, The Netherlands) by transcervical i.u. infusion, $500 \mu \mathrm{g}(2$ $\mathrm{ml}$ ) of cloprostenol (a synthetic analogue of $\mathrm{PGF}_{2 \alpha}$ ) by i.m. injection (Estrumate, Schering-Plough Animal Health, Pointe Claire, Quebec, Canada), or no treatment. Because of the different nature and routes of administration of the test treatments, blinding was not possible. Therefore, no placebo was used for the negative controls. Products were stored and handled according to label directions. Both test products had zero milk withhold and $2 \mathrm{~d}$ of meat withdrawal after treatment. The treatments were assigned within herd, using a computer-generated random number list to produce a sequential treatment allocation chart. Within each herd, each consecutive group of three treatments was balanced for experimental group.

\section{Follow-up Examinations}

Each animal was reexamined $14 \mathrm{~d}$ after diagnosis and treatment (between 34 and 47 DIM), exactly as at enrollment. Clinical cure was initially defined as the absence of any pus discharge at the follow-up examination. Animals that were not clinically cured received a second dose of the same treatment as initially administered. These animals were then examined for a third and final time after an additional $14 \mathrm{~d}$ (between 48 and 61 DIM; $28 \mathrm{~d}$ after initial enrollment). Any animal that still had pus discharge at the third examination was recorded as a clinical failure and received both cephapirin i.u. and $\mathrm{PGF}_{2 \alpha}$ simultaneously. For animals that were initially untreated and still had any purulent discharge $14 \mathrm{~d}$ later, both cephapirin i.u. and $\mathrm{PGF}_{2 \alpha}$ were administered simultaneously, and the protocol ended as a clinical failure. The effect of clinical resolution (and, therefore, the number of treatments) was controlled by inclusion in the models of reproductive performance. Therefore, all cows were retained in the analysis of pregnancy rate; none was excluded on the basis of clinical failure.

Based on the case definition of endometritis derived previously, clinical resolution was subsequently defined as the absence of muco-purulent or worse discharge and cervical diameter $\leq 7.5 \mathrm{~cm}$ at the second examination. This resulted in 42 cows that had mucus with flecks of pus at the second examination receiving 
a second treatment, although they did not have clinical endometritis. These cows were not included in the present analysis.

After termination of the treatment protocol, all cows followed the normal herd reproductive management practices in the breeding period. This included various individual treatments or systematic herd programs of one or more injections of $\mathrm{PGF}_{2 \alpha}$ and/or GnRH for estrous detection or synchronization, or synchronization of ovulation. Data were not collected on the number of $\mathrm{PGF}_{2 \alpha}$ injections that a cow may have received following the treatment protocol. Insemination and culling dates and pregnancy data were collected using onfarm data recording forms and DHI records. Reproductive performance and culling data on all animals were collected until 7 mo after the last cow was enrolled. Observations of time to pregnancy for cows that were culled during the trial before pregnancy were censored on the date of culling. For cows that were not pregnant at the termination of data collection, observations were censored on that date.

The following outcomes were measured to assess reproductive performance: interval from calving to first insemination (days to first service), first service pregnancy risk (\%), interval from calving to pregnancy (days open), cumulative pregnancy risk (\%), number of inseminations per pregnancy in pregnant cows, and removal risk for reproductive failure (\%). Pregnancy was diagnosed by transrectal palpation of the uterus at least $35 \mathrm{~d}$ post-breeding. Cumulative pregnancy risk was the proportion of cows enrolled in the trial that eventually became pregnant in that lactation. Removal risk for reproductive failure was the proportion of cows enrolled in the trial that were bred at least three times but did not become pregnant and were culled.

\section{Data Management and Statistical Analysis}

All analyses were performed with SAS, version 8.0 (1999). Simple associations of treatment with binary outcomes were tested using the chi-square statistic. If a cell expected frequency was less than five, Fisher's exact test was substituted for chi-square. Final models of dichotomous outcomes, including covariates, were generated using multivariable logistic regression (the GENMOD procedure in SAS, with binomial distribution, and the logit link function). The count of inseminations in pregnant cows was also modeled with the GENMOD procedure in SAS, but specifying a Poisson distribution, log link, and offset equal to the natural logarithm of the number of cows in each stratum. The effect of correlation of cows within a herd (clustering) was adjusted for in both the binary and count models, using generalized estimating equations with compound symmetry correlation structure to produce robust standard errors (McDermott et al., 1994; Shoukri and Pause, 1999).

Kaplan-Meier (product limit) survival function estimates (the LIFETEST procedure in SAS) were used to calculate crude associations of treatment with median time to first breeding and pregnancy, and to generate graphs of cumulative pregnancy risk over time using spline curve-fitting in Sigma-Plot (version 5.0; SPSS Inc., 1999). The effects of treatment on time to first breeding and pregnancy were analyzed with multivariable survival analysis using Cox's proportional hazards regression (the PHREG procedure in SAS). Both of these survival analysis procedures are nonparametric, so they do not depend on any specification of the underlying distribution of the data. Adjustment for intraherd correlation was made by applying the proportional hazards leverage macro (PHLEV) in SAS to produce robust standard errors for the proportional hazards regression (Bergstralh et al., 1993; Therneau, 1993).

Although survival analysis models time to an event, in Cox's model, the output is expressed as a hazard ratio (HR) - the relative risk of pregnancy between groups in a very small time interval (i.e., the "daily probability of conception"; Fourichon et al., 2000). Actual median days open, adjusted for covariates, were taken from the survival function estimates produced by the PHREG baseline option, at the point where the survival function estimates stabilized below 0.5.

The main effect of interest was the impact of treatment on time to pregnancy in cows with clinical endometritis. Categorical dummy variables were created for infusion and $\mathrm{PGF}_{2 \alpha}$, with untreated cows with endometritis as the referent. Comparisons between cephapirin and $\mathrm{PGF}_{2 \alpha}$ in survival models were made with the "test" statement in the main proportional hazards regression. The test of equality of effect between the two positive treatments was adjusted for covariates in the model, but not for the effect of intraherd correlation because the contrast test is not available in the PHLEV macro. The dominant ovarian structure palpated at the initial examination was coded with dummy variables for corpus luteum (CL), follicle, or cyst, with no structures as the referent. In the multivariable analyses of reproductive performance, adjustment for intraherd correlation was made in all models by including herd as a random effect. In addition to the main effect of treatment, the effects of prior reproductive disorders, parity group, ovarian structure at treatment, and clinical cure were offered to the models as covariates. These models were built by manual backward stepwise elimination, removing the covariate 
Table 1. Selected clinical findings in Holstein cows with clinical endometritis examined biweekly between 20 and 61 DIM.

\begin{tabular}{|c|c|c|c|c|}
\hline \multirow[b]{2}{*}{ Variable } & \multirow[b]{2}{*}{$\begin{array}{l}\text { Initial } \\
\text { treatment }^{1}\end{array}$} & \multicolumn{3}{|c|}{ Examination } \\
\hline & & $\begin{array}{l}\text { Initial } \\
20 \text { to } 33 \text { DIM }\end{array}$ & $\begin{array}{l}\text { Second } \\
34 \text { to } 47 \text { DIM }\end{array}$ & $\begin{array}{l}\text { Third }^{2} \\
48 \text { to } 61 \text { DIM }\end{array}$ \\
\hline $\mathrm{n}$ & & 309 & 223 & 53 \\
\hline $\begin{array}{l}\text { Proportion with } \\
\text { cervix }>7.5 \mathrm{~cm}\end{array}$ & $\begin{array}{l}\text { None } \\
\text { i.u. } \\
\text { PGF }\end{array}$ & $\begin{array}{l}45 \\
35 \\
40\end{array}$ & $\begin{array}{l}5 \\
1 \\
0\end{array}$ & $\begin{array}{l}0 \\
0 \\
0\end{array}$ \\
\hline $\begin{array}{l}\text { Uterine horn size } \\
(\mathrm{cm})\end{array}$ & $\begin{array}{l}\text { None } \\
\text { i.u. } \\
\text { PGF }\end{array}$ & $\begin{array}{l}6.6 \\
6.4 \\
6.1\end{array}$ & $\begin{array}{l}4.8 \\
4.5 \\
4.3\end{array}$ & $\begin{array}{l}3.4 \\
4.5 \\
3.8\end{array}$ \\
\hline $\begin{array}{l}\text { Proportion with } \\
\text { asymmetric uterus }\end{array}$ & $\begin{array}{l}\text { None } \\
\text { i.u. } \\
\text { PGF }\end{array}$ & $\begin{array}{l}66 \\
62 \\
63\end{array}$ & $\begin{array}{l}34 \\
30 \\
28\end{array}$ & $\begin{array}{l}20 \\
24 \\
21\end{array}$ \\
\hline $\begin{array}{l}\text { Proportion with } \\
\text { uterus not entirely } \\
\text { in pelvis }\end{array}$ & $\begin{array}{l}\text { None } \\
\text { i.u. } \\
\text { PGF }\end{array}$ & $\begin{array}{l}77 \\
69 \\
74\end{array}$ & $\begin{array}{l}57 \\
42 \\
41\end{array}$ & $\begin{array}{l}27 \\
40 \\
38\end{array}$ \\
\hline $\begin{array}{l}\text { Ovarian structure } \\
\text { None }\end{array}$ & $\begin{array}{l}\text { None } \\
\text { i.u. } \\
\text { PGF }\end{array}$ & $\begin{array}{l}35 \\
29 \\
40\end{array}$ & $\begin{array}{l}10 \\
18 \\
22\end{array}$ & $\begin{array}{r}10 \\
29 \\
4\end{array}$ \\
\hline CL & $\begin{array}{l}\text { None } \\
\text { i.u. } \\
\text { PGF }\end{array}$ & $\begin{array}{l}35 \\
41 \\
44\end{array}$ & $\begin{array}{l}60 \\
46 \\
51\end{array}$ & $\begin{array}{l}80 \\
52 \\
79\end{array}$ \\
\hline Follicle & $\begin{array}{l}\text { None } \\
\text { i.u. } \\
\text { PGF }\end{array}$ & $\begin{array}{l}22 \\
26 \\
13\end{array}$ & $\begin{array}{l}29 \\
29 \\
22\end{array}$ & $\begin{array}{l}10 \\
19 \\
17\end{array}$ \\
\hline Cyst & $\begin{array}{l}\text { None } \\
\text { i.u. } \\
\text { PGF }\end{array}$ & $\begin{array}{l}9 \\
4 \\
4\end{array}$ & $\begin{array}{l}2 \\
8 \\
5\end{array}$ & $\begin{array}{l}0 \\
0 \\
0\end{array}$ \\
\hline
\end{tabular}

${ }^{1}$ None $=$ Untreated cows with endometritis; i.u. = cephapirin intrauterine infusion; $\mathrm{PGF}=$ prostaglandin $\mathrm{F}_{2 \alpha}$ injection.

${ }^{2}$ Only cows that were not clinically cured at the second examination received the third examination.

with the largest $P$ value at each step until all covariates were significant at $P<0.10$. If one level of a dummy variable was significant, all levels were retained.

Involution was ongoing during the enrollment period, and because these changes were expected to influence the response to treatment, it was decided a priori to examine the results stratified into earlier (20 to 26 DIM) and later (27 to 33 DIM) halves of the enrollment period, as well as overall.

\section{RESULTS}

Of 316 cows with endometritis, 89 (28\%) were randomly assigned to receive no treatment initially, 111 (35\%) received cephapirin i.u., and $116(37 \%)$ received $\mathrm{PGF}_{2 \alpha}$. The apparent inequality of treatment assignments was attributable to post-hoc reclassification of cows on the basis of the case definition of endometritis derived from the data (LeBlanc et al., 2002). There was no association between treatment assignment and parity group $(P=0.61)$, or time of enrollment (first or second week of the period; $P=0.59$ ).

There were no apparent differences between treatment groups in gross involution of the uterus and cervix following treatment (Table 1). Although there were no cows without endometritis with which to compare at the second and third examinations, cows with endometritis achieved gross involution (cervix $<7.5 \mathrm{~cm}$ in diameter and uterine horns approximately $4 \mathrm{~cm}$ in diameter), on average, by the time of the second examination. Ovarian structures were more variable, but there were no clear tendencies for differences between treatment groups.

Clinical resolution was defined as the absence of muco-purulent or worse uterine discharge and cervical diameter $\leq 7.5 \mathrm{~cm}$ at the second examination (Table 2). There were 223 animals available to assess resolution of clinical signs. Ninety- three cows (29\%) did not have appropriate data for this assessment. Of these, 15 cows were culled before the follow-up examination, but the remainder were not examined because of omission, 
Table 2. Logistic regression models of the clinical resolution of endometritis after initial treatment with intrauterine (i.u.) antimicrobial or prostaglandin $\mathrm{F}_{2 \alpha}$ between 20 and 33 DIM in cows with endometritis. Clinical resolution was defined as the absence of muco-purulent or worse uterine discharge and cervical diameter $\leq 7.5 \mathrm{~cm} 14$ days later. ${ }^{1}$

\begin{tabular}{|c|c|c|c|c|c|c|}
\hline \multirow[b]{2}{*}{ Factor } & \multicolumn{2}{|c|}{$\begin{array}{c}\text { Overall } \\
(\mathrm{n}=222)\end{array}$} & \multicolumn{2}{|c|}{$\begin{array}{l}\text { Treated between } \\
20 \text { and } 26 \text { DIM } \\
\quad(\mathrm{n}=120)\end{array}$} & \multicolumn{2}{|c|}{$\begin{array}{l}\text { Treated between } \\
27 \text { and } 33 \text { DIM } \\
\quad(\mathrm{n}=102)\end{array}$} \\
\hline & $\begin{array}{l}\text { Odds ratio } \\
(95 \% \mathrm{CI})^{2}\end{array}$ & $P$ & $\begin{array}{l}\text { Odds ratio } \\
(95 \% \text { CI })\end{array}$ & $P$ & $\begin{array}{l}\text { Odds ratio } \\
(95 \% \text { CI })\end{array}$ & $P$ \\
\hline Cephapirin i.u. ${ }^{3}$ & $\begin{array}{l}1.15 \\
(0.51-2.59)\end{array}$ & 0.73 & $\begin{array}{l}0.98 \\
(0.87-3.50)\end{array}$ & 0.97 & $\begin{array}{l}1.67 \\
(0.56-5.0)\end{array}$ & 0.38 \\
\hline Prostaglandin $\mathrm{F}_{2 \alpha}{ }^{3}$ & $\begin{array}{l}0.87 \\
(0.39-1.93)\end{array}$ & 0.73 & $\begin{array}{l}0.98 \\
(0.30-3.19)\end{array}$ & 0.97 & $\begin{array}{l}0.79 \\
(0.31-1.99)\end{array}$ & 0.61 \\
\hline
\end{tabular}

${ }^{1}$ Models are adjusted for the effects of a palpable CL or follicle and intraherd correlation.

${ }^{2} 95 \%$ confidence interval.

${ }^{3}$ Treatment effects are relative to untreated cows with endometritis.

attributable in most cases to cancellation of scheduled herd visits. An additional 19 of 51 cows (37\%) that received a second treatment did not undergo the third examination. In the case of cows that were initially untreated but did not cure and received both treatments at the second examination, there appears to have been confusion among clinicians over the need to perform the third assessment. Notwithstanding these omissions, the crude rates of resolution of clinical signs were high (approximately 77\%) for both initial and second treatments and did not differ $(P>0.9)$ among treatment groups or across times of enrollment. Furthermore, clinical resolution was not a significant effect in subsequent models of reproductive performance. Therefore, in those models, cows were not stratified on repeat treatment status.

There were no significant simple associations between treatment and any absolute measure of reproductive performance in cows with endometritis (Table 3 ). However, after 26 DIM, untreated cows tended ( $P$ $=0.07$ ) to have longer median days to pregnancy than cows treated with either antibiotic infusion or $\mathrm{PGF}_{2 \alpha}$.

Overall, there was no significant effect of either treatment on time to pregnancy, relative to controls (Table 4). However, cephapirin tended to reduce time to pregnancy by $29 \%$, relative to untreated cows $(P=$ $0.14)$, and was significantly better overall than $\mathrm{PGF}_{2 \alpha}$ $(P=0.04)$. There were several biologically plausible modifiers of the effects of treatment, including the interval postpartum at treatment and whether the cow had a palpable CL at the time of treatment. The effect of treatment, infusion in particular, tended to depend on the time of treatment after calving (interaction of cephapirin and week of the study period; $P=0.12$ ). Therefore, the results were stratified by week of the study period, and within these strata, by cows' ovarian status (Table 4).
For cows with treatments initiated between 20 and 26 DIM, overall there were no significant differences in pregnancy rate among the three treatment groups. Even though endometritis in this period is associated with impaired fertility, neither treatment shortened the time to pregnancy relative to untreated cows with endometritis. Across all substrata, there was no significant benefit of either treatment administered between 20 and 26 DIM (Table 4). Moreover, in this time frame, among cows that did not have a palpable CL, administration of $\mathrm{PGF}_{2 \alpha}$ had an apparent significant deleterious effect on pregnancy rate.

For cows with treatments initiated between 27 and 33 DIM, those treated with the cephapirin i.u. had a pregnancy rate $63 \%$ higher $(P=0.01)$ than untreated cows with endometritis, although this was not statistically different $(P=0.19)$ from the $18 \%$ improvement in cows treated with $\mathrm{PGF}_{2 \alpha}$ (Table 4). The effect of cephapirin was significantly better than no treatment in cows with a palpable CL but not in cows without a CL. In the second week of the study period, either treatment had a more beneficial effect in cows with a CL than in cows without. Cows treated with cephapirin consistently had numerically higher pregnancy rates than those treated with $\mathrm{PGF}_{2 \alpha}$, but those differences were not statistically significant.

The effect of clinical resolution at follow-up examination did not contribute $(P=0.75)$ to models of treatment effects on pregnancy rate (Table 4). Similarly, cows with endometritis that had purulent discharge had a similar $(P=0.63)$ pregnancy rate to cows with muco-purulent discharge, when treatment was included in the model. Parity group and ovarian structures were significant covariates in the models of time to pregnancy, clinical cure, interval to first breeding and first service pregnancy risk. For example, for each increase of one parity group, cows had a $15 \%$ reduction 
Table 3. Crude associations of treatment with intrauterine (i.u.) antimicrobial or prostaglandin $\mathrm{F}_{2 \alpha}$ between 20 and 33 DIM with absolute measures of reproductive performance in Holstein cows with clinical endometritis.

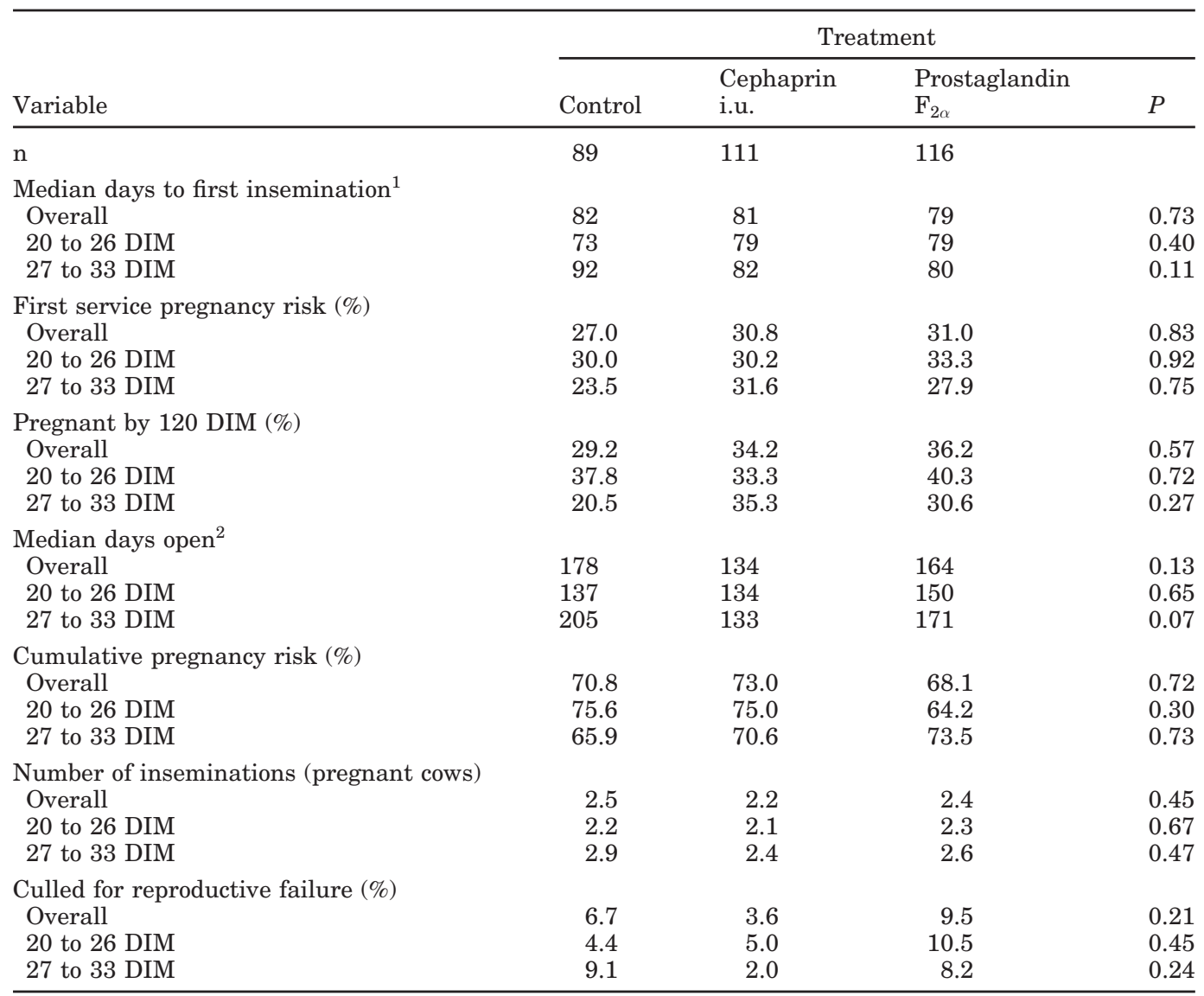

${ }^{1}$ Survival analysis: includes both cows that were and were not bred.

${ }^{2}$ Survival analysis: includes both cows that did and did not become pregnant.

in pregnancy rate $(\mathrm{HR}=0.85 ; P=0.02)$. However, there was no interaction of treatment with parity $(P=0.83)$. Cows with a palpable follicle as the dominant ovarian structure had a significantly increased pregnancy rate (HR $=1.4 ; P=0.01)$, while those with a CL tended to have increased pregnancy rate $(\mathrm{HR}=1.3 ; P=0.11)$, relative to cows with no palpable structures at the time of treatment.

Because $\mathrm{PGF}_{2 \alpha}$ exerts its primary effect through luteolysis, in the absence of data on progesterone levels, the effect of treatment of cows with endometritis was stratified on the basis of the presence of a palpable CL (Table 4). In cows with a palpable CL, cephapirin i.u. and $\mathrm{PGF}_{2 \alpha}$ treatments increased pregnancy rate by $75 \%(P=0.003)$ and $43 \%(P=0.21)$, respectively, relative to untreated cows. Although only the former was significantly different from untreated cows, the effects of the treatments were not different from each other $(P=0.36)$. Conversely, in cows without a palpable CL, neither treatment shortened time to pregnancy relative to controls, and $\mathrm{PGF}_{2 \alpha}$ tended $(P=0.09)$ to prolong days open.

Figure 1 illustrates that the differences in cumulative pregnancy rate were slight until approximately 130 DIM. Adjusted for the effect of parity group, estimated median days open and their 95\% confidence intervals were 172 (142 to 222), 134 (115 to 166), and $165 \mathrm{~d}$ (116 to 291) for untreated, cephapirin, and $\mathrm{PGF}_{2 \alpha}$ groups, respectively.

In multivariable models (not shown), there were no significant differences between treatment groups in time to first insemination, pregnancy risk at first insemination, the number of inseminations per pregnant cow, or culling risk for reproductive failure.

\section{DISCUSSION}

This study is one of the largest randomized clinical trials of therapy for postpartum endometritis in dairy 
Table 4. Proportional hazards regression models of the effect treatment with intrauterine (i.u.) antimicrobial or prostaglandin $\mathrm{F}_{2 \alpha}$ on relative pregnancy rate in Holstein cows with clinical endometritis between 20 and 33 DIM. Endometritis was defined as the presence of purulent uterine discharge or cervical diameter > 7.5 cm, or the presence of muco-purulent discharge after 26 DIM. ${ }^{1}$

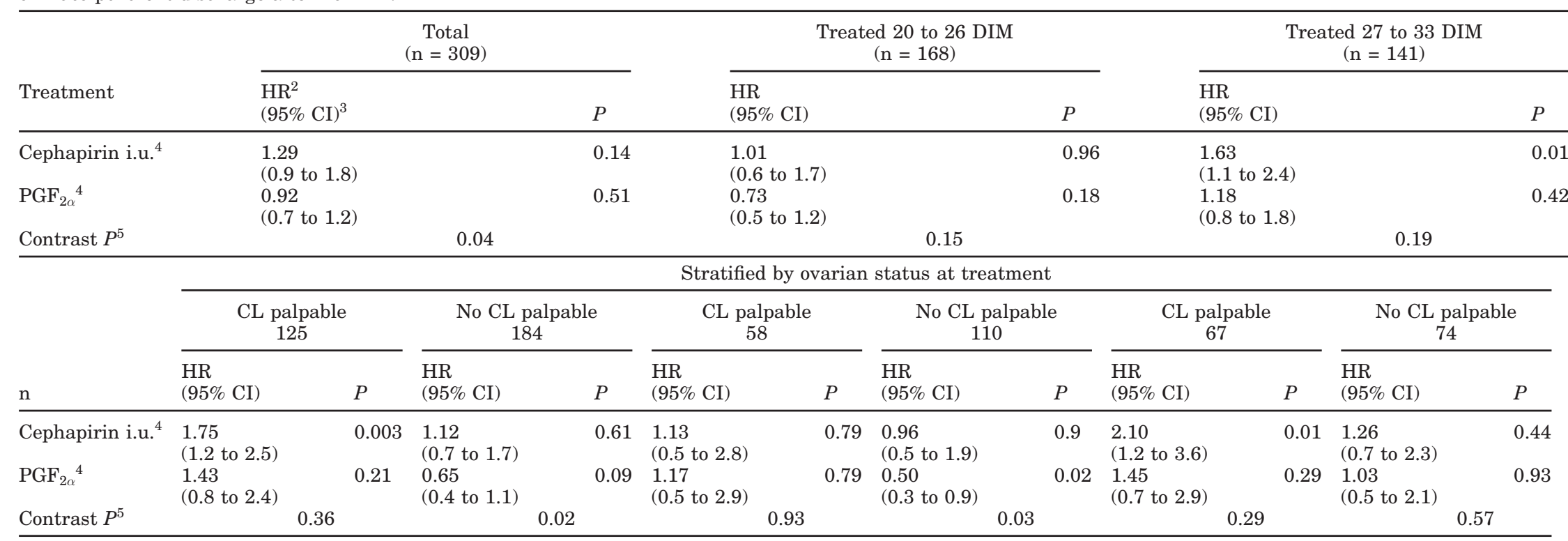

${ }^{1}$ Models are adjusted for the effects of parity group, presence of a palpable CL or follicle, and intraherd correlation.

${ }^{2} \mathrm{HR}=$ Hazard ratio for pregnancy (relative pregnancy rate).

${ }^{3} 95 \%$ confidence interval.

${ }^{4}$ Each treatment is measured relative to the referent of untreated cows with endometritis.

${ }^{5}$ Probability associated with the hypothesis that the effects of infusion and prostaglandin are equal; not adjusted for the effect of herd. 


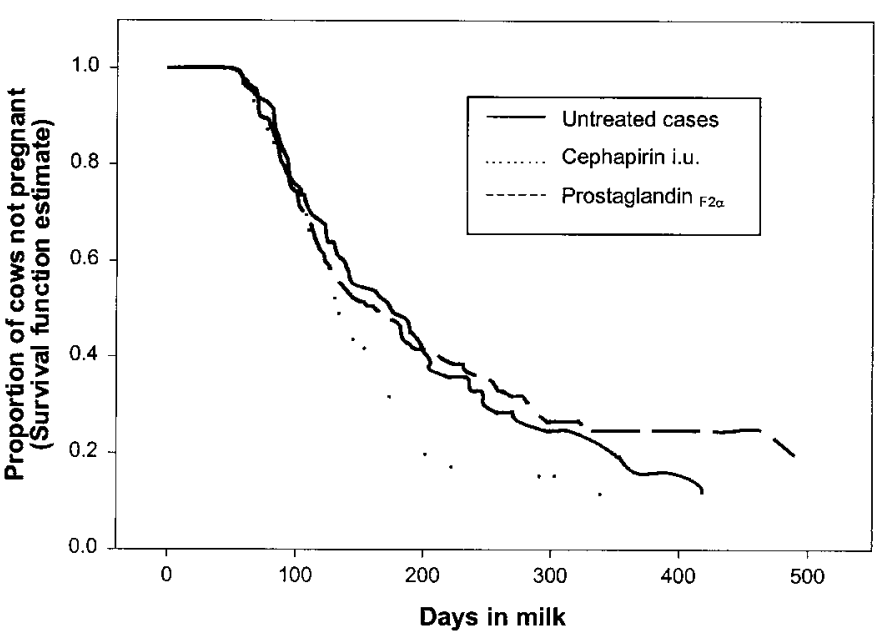

Figure 1. Survival curves of days to pregnancy in cows with clinical endometritis, diagnosed and treated between 20 and 33 DIM with one intrauterine infusion of $500 \mathrm{mg}$ of cephapirin benzathine, one intramuscular injection of prostaglandin $\mathrm{F}_{2 \alpha}$, or no treatment.

cows. It is the first to use a case definition for endometritis that was shown to identify cows with expected significant reduction in pregnancy rate (LeBlanc et al., 2002). It is one of few to include an untreated control group with both $\mathrm{PGF}_{2 \alpha}$ and i.u. antibiotic groups, and it is the first to use multivariable survival analysis, adjusted for intraherd correlation, to measure the effect of treatment on time to pregnancy. Despite the scope of this investigation, it does not conclusively resolve the controversy and incomplete knowledge regarding the merits of $\mathrm{PGF}_{2 \alpha}$ or i.u. antibiotic for treatment of endometritis. However, several practical refinements of the clinical approach to treatment of endometritis emerge.

\section{Impact of Treatment on Reproductive Performance}

Overall, neither treatment produced a significantly higher pregnancy rate relative to untreated cows. However, statistical power was less than ideal. Additionally, the effect of treatment depended on the interval postpartum, and the presence of a CL at treatment. Because the interval from calving to treatment was known with certainty, and because it is associated with the underlying processes of involution and resumption of the estrous cycle, results were first stratified into the early (20 to $26 \mathrm{DIM}$, inclusive) and later (27 to 33 DIM, inclusive) halves of the study period. This demarcation should not be taken as absolute.

In the early half of the enrollment period (20 to 26 DIM), there was no significant benefit of either treatment on time to pregnancy. Moreover, use of $\mathrm{PGF}_{2 \alpha}$ to treat cows with endometritis in that period in the absence of a CL was associated with a significant reduction in pregnancy rate. Even though cows at 20 to 26 DIM had clinical abnormalities associated with a reduction in pregnancy rate relative to cows without endometritis, neither treatment shortened time to pregnancy relative to doing nothing. LeBlanc et al. (2002) reported that cows with muco-purulent or worse uterine discharge or cervical diameter $>7.5 \mathrm{~cm}$ that persisted beyond 26 DIM had a more pronounced reduction in pregnancy rate than cows with endometritis diagnosed between 20 and 26 DIM. Together, the current and companion study support the likelihood that a high proportion of cows have spontaneous resolution of endometritis until at least $4 \mathrm{wk}$ postpartum. Conversely, if clinical signs associated with increased time to pregnancy are still present after $4 \mathrm{wk}$, the condition may be more responsive to treatment.

Between 27 and 33 DIM, cows treated with cephapirin i.u. had a significantly higher pregnancy rate than untreated cows. It is likely that there were unmeasured effects in the uterine environment such as the extent or degree of inflammation (Bonnett et al., 1993) and the reestablishment of normal hypothalamic, pituitary, ovarian, and uterine hormonal activity that interact with treatment. However, given the known mechanism of action of $\mathrm{PGF}_{2 \alpha}$ but the absence of progesterone measurements, cows with endometritis were stratified on the presence or absence of a palpable CL at the time of treatment. The effect of both treatments was enhanced in cows with a CL. Arguably, cows that have reestablished cyclicity (as evidenced by a CL) are advancing in the process of involution, are likely to spontaneously resolve endometritis in the short term, and may not benefit from exogenous therapy. However, in cows with a CL, cephapirin significantly increased pregnancy rate relative to untreated cases. It would be prudent not to ignore the estimated $45 \%$ increase in pregnancy rate among cows with a CL that received $\mathrm{PGF}_{2 \alpha}$, even though this effect was not statistically different from either of the other two treatment groups. Although i.u. antimicrobial cannot be expected to sterilize the uterus (Bretzlaff, 1987), it may reduce the bacterial load to a point where uterine defenses gain dominance and the inflammatory stimulus is reduced. Prostaglandin $\mathrm{F}_{2 \alpha}$ likely achieves the same end by reducing bacterial numbers through the cleansing effects of estrus-related uterine and cervical changes and the favorable influence of decreased progesterone level on uterine phagocytes. These effects, particularly that of cephapirin, appear to be potentiated by the resumption of cyclicity.

Interestingly, the pregnancy rate curves (survival function estimates) did not appear to separate between treatment groups until approximately 130 DIM (Fig- 
ure 1), suggesting that the difference in pregnancy rate between cephapirin and the other two groups was largely driven by events later in the breeding period. It is not clear how differences in effect of treatment for endometritis administered at approximately 30 DIM should be manifest over $100 \mathrm{~d}$ later. This period coincides with return to positive energy balance and increasing body condition in high- producing dairy cows, which influences the estrous cycle and fertility (Butler and Smith, 1989; Butler, 2000) and may plausibly interact with a residual effect of endometritis. Effective treatment of endometritis in the postpartum period may reduce the number of cows with lingering impairment of fertility in the period (chronic subclinical endometritis). There is preliminary evidence that subclinical endometritis is prevalent early in the breeding period, and that it may exert a significant deleterious effect on reproductive performance (Gilbert et al., 1998).

In cows with endometritis past 4 wk postpartum, but without a CL, neither treatment significantly shortened time to pregnancy. The lack of effect of $\mathrm{PGF}_{2 \alpha}$ in cows without a CL does not support a direct uterotonic effect of $\mathrm{PGF}_{2 \alpha}$ in postpartum cows, in contrast to suggestions repeated frequently in the literature (Steffan et al., 1984; Young et al., 1984). If the principal effect of $\mathrm{PGF}_{2 \alpha}$ is to cause luteolysis (and thereby induce estrus), it is logical that this treatment is not different from no treatment in cows without a $\mathrm{CL}$. This finding is in agreement with numerous studies that have assessed the putative therapeutic effect of $\mathrm{PGF}_{2 \alpha}$ in "abnormal" cows in the first 5 wk postpartum, all of which have failed to find statistically significant benefits in reproductive performance compared with untreated cows (Benmrad and Stevenson, 1986; Stevenson and Call, 1988a; McClary et al., 1989; Archbald et al., 1990; Glanvill and Dobson, 1991; Risco et al., 1994). However, as in the present study, the numbers of cows did not provide the statistical power to detect moderate differences between groups.

The negative effect on pregnancy rate of early (between 20 and 26 DIM) treatment with $\mathrm{PGF}_{2 \alpha}$ of cows that did not have a CL was unexpected. It is biologically sensible that $\mathrm{PGF}_{2 \alpha}$ would have no benefit in the absence of a responsive CL, and it is not clear how the drug produced an apparently harmful effect on fertility. However, Gay and Upham (1994) reported that administration of $\mathrm{PGF}_{2 \alpha}$ at approximately $25 \mathrm{DIM}$ to clinically normal cows with a palpable CL significantly reduced first service pregnancy risk. They speculated that the treatment might have had an unspecified harmful effect on early follicular development. Similarly, Tenhagen and Heuwieser (1999) found that biweekly administration of $\mathrm{PGF}_{2 \alpha}$ from 22 to $28 \mathrm{DIM}$ until first breeding at 50 to 60 DIM reduced first service conception risk from $50 \%$ to $35 \%$, in cows both with and without vaginoscopically diagnosed endometritis. The first postpartum ovulation typically occurs about 3 wk after calving in dairy cows and is followed by a short ( $<10$ d) luteal phase (Stevenson, 1997). It has been reported that conditions including endometritis delay the process of reinitiation of cyclicity (Stevenson and Call, 1988b). It is possible that exogenous $\mathrm{PGF}_{2 \alpha}$ during this critical period of transitional cycles may cause premature lysis of luteal tissue, depriving the hypothalamus, pituitary gland, or ovaries of progesterone needed to reestablish normal endocrine signaling and ovarian function. Practically, this reinforces the conclusion that cows do not benefit from treatment with $\mathrm{PGF}_{2 \alpha}$ unless a CL is present. Given the imperfect ability to identify CL by palpation (Ott et al., 1986; Kelton et al., 1991), cows with or without endometritis should not be treated with $\mathrm{PGF}_{2 \alpha}$ until at least $4 \mathrm{wk}$ postpartum.

It is difficult to compare these findings to others because there are few reports that used a reproductive performance-based case definition of endometritis, included negative controls, and used survival analysis or logistic regression to analyze time to pregnancy. Crudely, the results are consistent with most published reports, which have failed to document significant improvements in reproductive performance associated with treatment of endometritis with either i.u. antibiotics or $\mathrm{PGF}_{2 \alpha}$. It was particularly surprising that, when adjusted for significant effect modifiers, the only significant improvements in pregnancy rate were associated with the i.u. antibiotic. However, a separate study also reported a beneficial effect of cephapirin i.u. on reproductive performance among cows with a history of retained placenta, stillborn calf, or vulval discharge (McDougall, 2001). These results are in contrast to the conclusions of several reviews of endometritis therapy that found little support for use of i.u. antibiotics, and at least circumstantial evidence in favor of $\mathrm{PGF}_{2 \alpha}$ (Gustafsson, 1984; Bretzlaff, 1987; Gilbert and Schwark, 1992; Olson, 1996). Had the present study not included an untreated control group, it would have concluded, with few exceptions, that there was simply no significant difference between cephapirin i.u. and $\mathrm{PGF}_{2 \alpha}$.

In one study of vaginoscopically diagnosed endometritis treated at 13 or 21 DIM, there was no effect of i.u. infusion of a low dose of either oxytetracycline or penicillin on time to pregnancy, relative to untreated cases (Thurmond et al., 1993). There are only two other published reports that compared the effects of i.u. antimicrobials, $\mathrm{PGF}_{2 \alpha}$ or no treatment on reproductive performance in cows with endometritis (Steffan et al., 
1984; Callahan and Horstman, 1987). In both studies, as here, overall there were no significant differences in days open or cumulative pregnancy risk between treatment groups, although Steffan et al. (1984) reported that combining groups, treated cows had a higher pregnancy rate than untreated cows with endometritis. In other studies of cows with endometritis, $\mathrm{PGF}_{2 \alpha}$ tended to produce higher cumulative pregnancy risk and lower mean days open than i.u. antimicrobials (Steffan et al., 1984; Vujosevic, 1984, as reported by Bretzlaff, 1987). However, in these trials, $\mathrm{PGF}_{2 \alpha}$ was given at 37, or at 19 and 30 DIM, respectively. Yet, in the study by Steffan et al. (1984), the most pronounced benefit of $\mathrm{PGF}_{2 \alpha}$ was in cows with circulating progesterone less than $1.5 \mathrm{ng} / \mathrm{ml}$ (i.e., no functional CL). Collectively, these results suggest that treatment of endometritis after approximately 30 DIM may improve reproductive performance.

\section{Resolution of Clinical Signs}

The rate of resolution of clinical signs was high and not affected by treatment. In other words, there were high rates of spontaneous resolution of purulent uterine discharge and cervical involution. These findings are in agreement with other studies, which have consistently failed to find differences in the rate of clinical cure between i.u. antibiotics and $\mathrm{PGF}_{2 \alpha}$ (Callahan and Horstman, 1987; Murray et al., 1990; Sheldon and Noakes, 1998), or between either therapy and no treatment (Callahan and Horstman, 1987). However, absence of discharge did not imply improved reproductive performance. In the present study, clinical cure was not significantly associated with pregnancy rate. Purulent discharge may be a marker for inflammatory changes in the uterus that reduce pregnancy rate and that may persist beyond the discharge itself (Bretzlaff, 1987; Gilbert et al., 1998). Only $4 \%$ of cows with endometritis had persistent purulent uterine discharge of any character $4 \mathrm{wk}$ after initial diagnosis, and after one or two treatments.

\section{Use of Rectal Palpation to Assess Ovarian Status and Its Effect on Treatment}

Caution is needed in interpreting the results of transrectal palpation of ovarian structures. In the context of postpartum cows in general, and treatment of endometritis in particular, there are two possible effects of true ovarian status. First, either the cow has resumed cyclicity at the time of the examination, or she has not. If estrous cycles are proceeding by 3 to 4 wk postpartum, this is favorable for fertility in general (Thatcher et al., 1973), and resolution of endometritis in particular. This is supported by the observation that either treatment, but especially cephapirin, produced higher pregnancy rates in cows with endometritis that had a CL (Table 4). Assessment of whether or not a cow is cyclic has been made in research settings on the basis of serial progesterone measurements (Benmrad and Stevenson, 1986). In clinical practice, cyclicity is crudely estimated by the presence of palpable follicles and CL that are consistent with ovarian activity. The present results suggest that this technique has some ability to distinguish cows in a meaningful way, but the sensitivity and specificity of palpation for assessment of cyclicity are unknown.

Second, if a postpartum cow truly has a functional $\mathrm{CL}$, this implies not only that she is cyclic, but also that she should be responsive to administration of $\mathrm{PGF}_{2 \alpha}$. However, the accuracy of rectal palpation to determine the presence of a functional CL is imperfect. A summary of four reports found the mean accuracy of palpation was $76 \%$ relative to progesterone assay, with a tendency for more false negative than false positive palpation findings (Ott et al., 1986). Conversely, Kelton et al. (1991) found that compared to the gold standard of a radioimmunoassay for progesterone in milk, palpation had mean sensitivity of $82.6 \%$ and specificity of $52.6 \%$. In that study, the true prevalence of functional luteal tissue was $77.4 \%$. Prostaglandin-sensitive luteal tissue is expected to be present from $\mathrm{d} 5$ to 17 of a typical 21-d bovine estrous cycle, or approximately $62 \%$ of the time on average. The true prevalence of prostaglandin-responsive CL in the present study population is unknown, but the apparent prevalence of CL in cows between 20 and 33 DIM, based on palpation, was approximately $45 \%$.

In the early postpartum period, reestablishment of a regular estrous cycle includes short, irregular cycles with follicular growth, but without ovulation and formation of a normal CL (Stevenson, 1997). Therefore, it is surprising that presence of a palpable follicle as the predominant ovarian structure during the enrollment period was consistently and significantly associated with higher pregnancy rate. This finding is supported by Bonnett et al. (1993), who found that presence of a palpable follicle at 26 DIM was significantly associated with increased probability of pregnancy by 120 DIM. It is possible that cows in which a follicle was identified as the dominant ovarian structure were in the peri-estrous period, indicating that they were cyclic, with the attendant benefits for uterine health associated with estrus (Gilbert and Schwark, 1992). Given a hierarchy in which a CL is considered dominant to a concurrent follicle, estral follicles would only be expected to be the predominant structure between d 18 and 21 of the cycle, or $14 \%$ of the time. In the 
present study, follicles were identified as the dominant ovarian structure approximately $20 \%$ of the time, making it unlikely that all of these cows were in proestrus or estrus. Therefore, it is possible that some CL were misclassified as follicles.

\section{Interpretation and Application of Results}

The present results illustrate a situation in which there may be a difference between statistical significance and biological or management significance (Galligan et al., 1991; Stewart et al., 1994). Rothman and Greenland (1998) make the case that adherence to arbitrary statistical hypothesis testing without consideration of estimation of effect may lead to type II errors (false negative) with respect to the biological hypothesis under consideration. There are many factors that influence reproductive performance, resulting in highly variable individual times to pregnancy in large groups of cows. This presents a considerable challenge to precise estimation of the effects of treatment of endometritis on reproductive performance that is unlikely to be resolved with a single clinical trial.

The sample size was estimated based on detection of a difference of $10 \mathrm{~d}$ to pregnancy, with a standard deviation of $30 \mathrm{~d}$. Overall, the crude differences in median days open between treatment groups were 14 to $44 \mathrm{~d}$. However, the standard deviation around time to pregnancy was larger than expected $(70 \mathrm{~d})$, which reduced the power of the calculated sample size to establish statistically significant differences between treatments, even if they exist. With such a large variance, detection of a difference of $10 \mathrm{~d}$ to pregnancy would require approximately 768 cows per treatment group (Martin et al., 1987). With a prevalence of $16 \%$, this would require examination of 14,000 cows, which was not feasible. Therefore, the trial was terminated once the planned sample size had been reached. The present dataset had the power to identify a difference of approximately 25 mean days open between treatment groups, which explains why most of the observed differences between treatment groups were not statistically significant. These figures are intended to provide a general context only, because the outcomes of interest were pregnancy rate and median days to pregnancy as calculated by survival analysis. Given a baseline of $205 \mathrm{~d}$ open in untreated cows, an HR for pregnancy of 1.18 (Table 4) implies a reduction of $37 \mathrm{~d}$ to pregnancy. Given an economic loss of CDN \$4.70/d open past 85 DIM (Plazier et al., 1997), this has considerable management importance. However, the confidence intervals around these estimates were wide. Moreover, HR are a relative measure, and conversion to absolute measures of performance is dependent on the value in the baseline group.

By treating cows early in the postpartum period, there may have been a bias against a significant beneficial effect of treatment with $\mathrm{PGF}_{2 \alpha}$, because a majority of cows did not have a CL (as best this could be determined by palpation). Given the results observed here, it is plausible that treatment later postpartum might increase the apparent efficacy of $\mathrm{PGF}_{2 \alpha}$ relative to i.u. antibiotics and no treatment, for mitigation of decreased pregnancy rate in cows with endometritis.

This study does not directly address the question of whether individual diagnosis and treatment of endometritis produces pregnancy rates superior to a systematic herd program of automatic $\mathrm{PGF}_{2 \alpha}$ injections before the breeding period, that is, through routine biweekly injections without diagnosis of endometritis (Tenhagen and Heuwieser, 1999; Heuwieser et al., 2000). Because of common use of breeding management programs, many cows in this study would have received one or more injections of $\mathrm{PGF}_{2 \alpha}$ following the study period. Although this could confound the effect of treatment of endometritis, when such interventions were made, they were independent of treatment for endometritis, and therefore were effectively a random effect at the cow level. In herds in which there was a systematic program of $\mathrm{PGF}_{2 \alpha}$ injections in the breeding period, this was accounted for by statistically controling for the herd effect.

\section{CONCLUSIONS}

There were meaningful improvements in pregnancy rate associated with treatment of endometritis under certain conditions. Surprisingly, this represents new information, because there have been so few trials published that included an untreated control group. There was no benefit on time to pregnancy of treatment of endometritis before 4 wk postpartum. Moreover, administration of $\mathrm{PGF}_{2 \alpha}$ between 20 and $26 \mathrm{DIM}$ to cows with endometritis that did not have a palpable CL was associated with a significant reduction in pregnancy rate. Between 27 and 33 DIM, cows with endometritis treated with cephapirin i.u. had a significantly shorter time to pregnancy than untreated cows, but the difference in pregnancy rate between cows treated by infusion and cows treated with $\mathrm{PGF}_{2 \alpha}$ was not statistically significant. In cows with endometritis that had a palpable CL, there was no significant difference in time to pregnancy between those treated by infusion and those treated with $\mathrm{PGF}_{2 \alpha}$. Both groups tended to have a higher pregnancy rate than in untreated cows. Cows should be selected for treatment of endometritis after 4 wk postpartum, using valid diagnostic criteria, in- 
cluding vaginoscopy. Further research is needed on the optimal timing and the need for repeated administration of $\mathrm{PGF}_{2 \alpha}$ as a treatment for endometritis.

In contrast to the view generally held by reviewers (Gilbert and Schwark, 1992; Olson, 1996), there is a niche, albeit limited, in which i.u. cephapirin is a beneficial treatment for endometritis. It is open to question whether any meaningful difference would exist between cephapirin and $\mathrm{PGF}_{2 \alpha}$ for treatment of endometritis beyond 33 DIM.

\section{ACKNOWLEDGMENTS}

Financial support was provided by Intervet International, Schering-Plough Animal Health, and Dairy Farmers of Ontario. We are grateful to all the participating dairy producers for their time and interest. Particular thanks are due to Jeromy TenHag and Jodi Wallace for excellent assistance with data management. We thank R. Bell, R. Dingwell, J. Jansen, D. Kelton, K. Lissemore, P. Menzies, D. Sandals, R. Swackhammer, J. Wichtel, and J. VanLeeuwen for enrolling and examining cows for the study.

\section{REFERENCES}

Archbald, L. F., T. Tran, P. G. A. Thomas, and S. K. Lyle. 1990. Apparent failure of prostaglandin F2 $\alpha$ to improve the reproductive efficiency of postpartum dairy cows that had experienced dystocia and/or retained fetal membranes. Theriogenology 34:1025-1034.

Benmrad, M., and J. S. Stevenson. 1986. Gonadotropin-releasing hormone and prostaglandin F2alpha for postpartum dairy cows: Estrous, ovulation, and fertility traits. J. Dairy Sci. 69:800-811.

Bergstralh, E., J. Kosanke, and T. Therneau. 1993. SAS Macro PHLEV: Leverage residuals matrix for proportional hazard regression. Mayo Clinic Tech Report 58, Mayo Clinic, Rochester, MN.

Bondurant, R. H. 1999. Inflammation in the bovine female reproductive tract. J. Dairy Sci. 82(Suppl. 2):101-110.

Bonnett, B. N., S. W. Martin, and A. H. Meek. 1993. Associations of clinical findings, bacteriological and histological results of endometrial biopsy with reproductive performance of postpartum dairy cows. Prev. Vet. Med. 15:205-220.

Bretzlaff, K. 1987. Rationale for treatment of endometritis in the dairy cow. Vet. Clin. North Am. Food. Anim. Pract. 3:593-607.

Brooks, G. 2000. Comparison of two intrauterine treatments for bovine endometritis. Vet. Rec. 146:25

Butler, W. R. 2000. Nutritional interactions with reproductive performance in dairy cattle. Anim. Reprod. Sci. 60-61:449-457.

Butler, W. R., and R. D. Smith. 1989. Interrelationships between energy balance and postpartum reproductive function in dairy cattle. J. Dairy Sci. 72:767-783.

Callahan, C. J., and L. A. Horstman. 1987. Treatment of early postpartum metritis in a dairy herd: response and subsequent fertility. Bovine Practitioner 22:124-128.

Callahan, C. J., and L. A. Horstman. 1993. Treatment of postpartum metritis in dairy cows caused by Actinomyces pyogenes. Bovine Practitioner 27:162-165.

Dohmen, M. J. W., J. A. C. M. Lohuis, G. Huszenicza, P. Nagy, and M. Gacs. 1995. The relationship between bacteriological and clinical findings in cows with subacute/chronic endometritis. Theriogenology 43:1379-1388.
Etherington, W. G., S. W. Martin, B. Bonnett, W. H. Johnson, R. B. Miller, N. C. Savage, J. S. Walton, and M. E. Montgomery. 1988. Reproductive performance of dairy cows following treatment with cloprostenol 26 and/or 40 days postpartum: a field trial. Theriogenology 29:565-575.

Fourichon, C., H. Seegers, and X. Malher. 2000. Effect of disease on reproduction in the dairy cow: A meta-analysis. Theriogenology 53:1729-1759.

Galligan, D. T., W. Chalupa, and C. F. Ramberg. 1991. Application of type I and II errors in dairy farm decision making. J. Dairy Sci. 74:902-910.

Gay, J. M., and G. L. Upham. 1994. Effect of exogenous prostaglandin F2 $\alpha$ in clinically normal postparturient dairy cows with a palpable corpus luteum. J. Am. Vet. Med. Assoc. 205:870-873.

Gilbert, R. O. 1992. Bovine endometritis: The burden of proof. Cornell Vet. 82:11-14.

Gilbert, R. O., and W. S. Schwark. 1992. Pharmacologic considerations in the management of peripartum conditions in the cow. Vet. Clin. North Am. Food. Anim. Pract. 8:29-56.

Gilbert, R. O., S. T. Shin, C. L. Guard, and H. N. Erb. 1998. Incidence of endometritis and effects on reproductive performance of dairy cows. Theriogenology 49:251(Abstr.).

Glanvill, S. F., and H. Dobson. 1991. Effect of prostaglandin treatment on the fertility of problem cows. Vet. Rec. 128:374-376.

Gustafsson, B. K. 1984. Therapeutic strategies involving antimicrobial treatment of the uterus in large animals. J. Am. Vet. Med. Assoc. 185:1194-1198.

Heuwieser, W., B. A. Tenhagen, M. Tischer, J. Luhr, and H. Blum. 2000. Effect of three programmes for the treatment of endometritis on the reproductive performance of a dairy herd. Vet. Rec. 146:338-341.

Kelton, D. F., K. E. Leslie, W. G. Etherington, B. N. Bonnett, and J. S. Walton. 1991. Accuracy of rectal palpation and of a rapid milk progesterone enzymeimmunoassay for determining the presence of a functional corpus luteum in subestrous dairy cows. Can. Vet. J. 32:286-291.

LeBlanc, S. J., T. F. Duffield, K. E. Leslie, G. P. Keefe, K. G. Bateman, J. S. Walton, and W. H. Johnson. Defining and diagnosing postpartum clinical endometritis, and its impact on reproductive performance. J. Dairy Sci. 85:1806:update at pagination.

Martin, S. W., A. H. Meek, and P. Willeberg. 1987. Veterinary Epidemiology-Principles and Methods. Iowa State University Press, Ames, IA.

McClary, D. G., M. R. Putnam, J. C. Wright, and J. L Sartin Jr. 1989. Effect of early postpartum treatment with prostaglandin F2 $\alpha$ on subsequent fertility in the dairy cow. Theriogenology 31:565-570.

McDermott, J. J., Y. H. Schukken, and M. M. Shoukri. 1994. Study design and analytic methods for data collected from clusters of animals. Prev. Vet. Med. 18:175-191.

McDougall, S. 2001. Effect of intrauterine antibiotic treatment on reproductive performance of dairy cows following periparturient disease. N.Z. Vet. J. 49:150-158.

Murray, R. D., J. D. Allison, and R. P. Gard. 1990. Bovine endometritis: Comparative efficacy of alfaprostol and intrauterine therapies, and other factors influencing clinical success. Vet. Rec. 127:86-90.

Olson, J. D. 1996. Metritis/endometritis: Medically sound treatments. Pages 8-14 in Proc. 29th Annu. Conf. Am. Assoc. Bov. Pract., San Diego, CA.

Ott, R. S., K. N. Bretzlaff, and J. E Hixon. 1986. Comparison of palpable corpora lutea with serum progesterone concentrations in cows. J. Am. Vet. Md. Assoc. 188:1417-1419.

Plazier, J. C. B., G. J. King, J. C. M. Dekkers, K. Lissemore. 1997. Estimation of economic values of indices for reproductive performance in dairy herds using computer simulation. J. Dairy Sci. 80:2775-2783.

Risco, C. A., L. F. Archbald, J. Elliott, T. Tran, and P. Chavatte. 1994. Effect of hormonal treatment on fertility in dairy cows with dystocia or retained fetal membranes at parturition. J. Dairy Sci. 77:2562-2569.

Rothman, K. J., and S. Greenland. 1998. Modern Epidemiology. 2nd ed., Lippincot Williams and Wilkins, Philadelphia, PA. 
SAS User's Guide: Statistics, Version 8 Developer's edition. 1999. SAS Inst., Inc., Cary, NC.

Sheldon, I. M., and D. E. Noakes. 1998. Comparison of three treatments for bovine endometritis. Vet. Rec. 142:575-579.

Shoukri, M. M., and C. A. Pause. 1999. Statistical Methods for the Health Sciences. 2nd ed., CRC Press, Boca Raton, FL.

Steffan, J., M. Agric, S. Adriamanga, and M. Thibier. 1984. Treatment of metritis with antibiotics or prostaglandin F2 alpha and influence of ovarian cyclicity in dairy cows. Am. J. Vet. Res. 45:1090-1094.

Stevenson, J. S., and E. P. Call. 1988a. Fertility of postpartum dairy cows after administration of gonadotropin- releasing hormone and prostaglandin F2alpha: A field trial. J. Dairy Sci. 71:19261933.

Stevenson, J. S., and E. P. Call. 1988b. Reproductive disorders in the periparturient dairy cow. J. Dairy Sci. 71:2572-2583.

Stevenson, J. S. 1997. Clinical reproductive physiology of the cow. Pages 257-267 in Current Therapy in Large Animal Theriogenology. R. S. Youngquist, ed. W.B. Saunders Co., Philadelphia, PA.
Stewart, S., J. Fetrow, S. Eicker. 1994. Analysis of current performance on commercial dairies. Compend. Contin. Educ. Pract. Vet. 16:1099-1103.

Tenhagen, B. A., and W. Heuwieser. 1999. Comparison of a conventional reproductive management programme based on rectal palpation and uterine treatment of endometritis with a strategic prostaglandin F2 alpha programme. J. Vet. Med. Ser. A 46:167-176

Thatcher, W. W., and C. J. Wilcox. 1973. Postpartum estrus as an indicator of reproductive status in the dairy cow. J. Dairy Sci. 56:608-610.

Therneau, T. 1993. Using a multiple events Cox model. Pages 114 in Proc. Biometrics Section Am. Stat. Assoc. Mtg., Hamilton, ON, Canada.

Thurmond, M. C., C. M. Jameson, and J. P. Picanso. 1993. Effect of intrauterine antimicrobial treatment in reducing calving-toconception interval in cows with endometritis. J. Am. Vet. Med. Assoc. 203:1576-1578.

Young, I. M., D. B. Anderson, and R. W. Plenderleith. 1984. Increased conception rate in dairy cows after early post partum administration of prostaglandin F2 alpha THAM. Vet. Rec. 115:429-431. 